\title{
AVALIAÇÃO DE MÉTODOS DE INOCULAÇÃO DE Phytophthora parasitica EM PLÂNTULAS E PLANTAS JOVENS DE CITROS*
}

\author{
AMAURI SIVIERO ${ }^{1}$, EDSON L. FURTADO ${ }^{2}$, LEONARDO P. BOAVA ${ }^{2}$, \\ DANILO V. BARBASSO ${ }^{1} \&$ MARCOS A. MACHADO ${ }^{1}$
}

${ }^{1}$ Centro Avançado de Pesquisa Tecnológica do Agronegócio de Citros 'Sylvio Moreira', Instituto Agronômico de

Campinas, Cx. Postal 04, 136490-970, Cordeirópolis, SP; ${ }^{2}$ Faculdade de Ciências Agronômicas,

Universidade Estadual Paulista, Cx. Postal 237, 18690-970, Botucatu, SP, e-mail: asiviero@ hotmail.com

(Aceito para publicação em 27/08/2002)

Autor para correspondência: Amauri Siviero

SIVIERO, A., FURTADO, E.L., BOAVA, L.P., BARBASSO, D.V. \& MACHADO, M.A. Avaliação de métodos de inoculação de Phytophthora parasitica em plântulas e plantas jovens de citros. Fitopatologia Brasileira 27:574-580. 2002.

\section{RESUMO}

Este trabalho teve como objetivo avaliar métodos de inoculação de Phytophthora parasitica em plântulas e plantas jovens de citros (Citrus spp.) visando sua utilização em estudos de resistência de porta-enxertos à gomose de Phytophthora. Os métodos de inoculação testados foram: contato planta sem ferimento-patógeno, casca destacada, inserção de disco de meio de cultura contendo micélio sob a casca, método do disco e inserção de agulha e palito infestados em plântulas e plantas jovens de citros. A resistência de genótipos à gomose pode ser avaliada em plântulas in vitro, através de inserção de agulha infestada. O método do disco e o da inserção sob casca foram os melhores quando utilizados em plantas jovens. A medida da área total da lesão é a variável ideal para avaliação da doença. No entanto, o comprimento da lesão pode ser utilizado na avaliação da doença em plântulas, plantas jovens e no campo.

Palavras-chave adicionais: gomose, metodologia, resistência, citros.

\section{ABSTRACT \\ Evaluation of inoculation methods for Phytophthora parasitica on citrus seedlings and young plants}

The present work was aimed at evaluating inoculation methods of Phytophthora parasitica on citrus (Citrus spp.) seedlings and young plants to determine the resistance of citrus rootstocks to Phytophthora gummosis. The following inoculation methods were tested: non-wounded host-pathogen contact, bark removal, insertion of culture disc under bark, insertion of inoculated needle or toothpick in the collar region and, the culture disc method. The assessment of resistance to gummosis in citrus seedlings produced in vitro was achieved by inserting an inoculatum in collar region. The disc method and insertion of disc under the bark were the best inoculation methods for young plants under both orchard and greenhouse conditions. The best variable for disease assessment had been the measurement of the total lesion area. Lesion length can also be used when carried out in nurseries and in the field.

\section{INTRODUÇÃO}

A gomose de Phytophthora, causada principalmente por Phytophthora parasitica Dastur, sinonímia Phytophthora nicotianae (Breda de Hann) (Tucker) var. parasitica (Dastur) Watherh., é uma das principais doenças dos citros (Citrus spp.) e ocorre em todas as regiões citrícolas do mundo (Graham \& Timmer, 1992). No Brasil, P. citrophthora (Sm. \& Sm.) Leonian e P. parasitica são os principais causadores da doença, sendo que $P$. parasitica predomina na grande maioria de viveiros e pomares comerciais, embora outras espécies de Phytophthora já tenham sido descritas como causadoras de gomose no Brasil. As condições favoráveis à infecção e ao desenvolvimento da doença são, principalmente, altas temperaturas, elevada umidade relativa do ar e umidade do

*Parte da tese de doutorado do primeiro autor. Faculdade de Ciências Agrárias. Universidade Estadual Paulista. solo (Fawcett \& Bitancourt, 1940; Feichtenberger, 2001).

A avaliação de grande número de materiais para resistência de porta-enxertos de citros à gomose deve ser precoce e envolver métodos de inoculação artificial. As metodologias utilizadas para avaliação da doença podridão de radicelas, outra importante doença do complexo citros-Phytophthora, envolvem adoção de métodos de infestação do substrato e não inoculação da parte aérea com os métodos propostos neste trabalho.

Diversas metodologias para avaliação de gomose em porta-enxertos de citros vêm sendo utilizadas, como: inserção de pedaços e discos de micélio do patógeno em frutos, ramos e tronco de plantas no campo (Fawcett, 1923; Klotz \& Fawcett, 1930; Rossetti, 1947); inserção de disco de micélio do patógeno sob a casca de plantas, semelhante ao processo de borbulhia de gemas (Grimm \& Hutchison, 1973; Afek \& Sztejnberg, 1990); injeção de suspensão de zoósporos em incisões realizadas na base das plantas (Whiteside, 1974; 
Avaliação de métodos de inoculação de Phytophthora parasitica em plântulas...

Smith et al., 1991); inserção de palito de dente infestado com patógeno (Aguilar-Vildoso \& Pompeu Junior, 1997) e inserção de agulha infestada com o patógeno in vitro e em plântulas (Siviero, 2001). O método do disco, descrito por Fawcett (1923) e empregado por Rossetti (1947), é o mais tradicionalmente utilizado em inoculações de Phytophthora spp. em plantas cítricas no campo.

A avaliação das lesões resultantes de inoculações de Phytophthora spp. pode ser feita medindo-se a área das lesões com o auxílio de planímetro (Klotz \& Fawcett, 1930); pela estimativa da porcentagem de anelamento do tronco (Smith et al., 1987); ou pela medição do comprimento e da largura das lesões e quantificação da goma (Fawcett, 1923).

Klotz \& Fawcett (1930) ressaltam que a simples multiplicação da medida do comprimento pela largura da lesão visando estimar a área de lesão provocada por Phytophthora spp. gera erros superestimando a área real entre 25 e $50 \%$. Siviero (2001), estudando métodos de avaliação de lesões em inoculações de $P$. parasitica, detectou que a área obtida relacionou-se positivamente com a medida do comprimento e da largura da lesão no lenho, apresentando coeficientes de correlação de 0,90 e 0,91 para os dois métodos de mensuração de lesão, planímetro e mesa digitalizadora.

Grimm \& Hutchison (1973) adotaram uma escala de notas de 1 a 5 para avaliação da doença em hastes de plantas jovens considerando-se a área de anelamento. Smith et al. (1987) propuseram uma escala diagramática, modificada de Grimm \& Hutchison (1973), com índices de doença que variam de 0 a 5 , considerando-se a porcentagem de anelamento, a formação de calos e a extensão da lesão.

Smith et al. (1987) avaliaram a resistência de cultivares de laranja doce (Citrus sinensis L.) e porta-enxertos à doença e concluíram que o método do disco de meio de cultura + micélio foi o mais eficiente quando comparado com os métodos que usaram zoósporos ou clamidósporos resultando em lesões de tamanho maior.

Smith et al. (1991) estudaram métodos de inoculação de Phytophthora spp. em porta-enxertos de citros inoculando plantas jovens em casa de vegetação e concluíram que o uso de clamidósporos como inóculo é eficiente e prático quando comparado ao uso do método do disco de meio + micélio ou suspensão de zoósporos; que o método do disco é severo devido ao alto potencial de inóculo e, que a densidade de inóculo pode afetar a suscetibilidade da planta ao patógeno.

O desenvolvimento de metodologias de inoculação que visam uma precoce avaliação da resistência de materiais vegetais a patógenos consiste numa importante etapa na seleção de genótipos superiores em programas de melhoramento. O presente estudo tem como objetivo selecionar métodos de inoculação que possibilitem avaliação da resistência de portaenxertos de citros à $P$. parasitica.

\section{MATERIAL E MÉTODOS}

O trabalho consistiu de quatro experimentos distintos, visando testar os diferentes métodos de inoculação de $P$. parasitica em plântulas e plantas jovens de citros. Em todos os experimentos foi utilizado o mesmo isolado de $P$. parasitica, LRS 23/97, procedente de Casa Branca, sendo obtido junto ao Laboratório de Sanidade Animal e Vegetal de Sorocaba, do Instituto Biológico.

\section{Inoculação in vitro de $P$. parasitica em porta-enxertos de citros}

Este experimento, cujo objetivo foi avaliar in vitro a reação de porta-enxertos de citros à $P$. parasitica, foi conduzido em delineamento inteiramente casualizado, com quatro tratamentos constituídos dos genótipos Poncirus trifoliata (L.) Raf. 'Davis A', citrange 'Carrizo' (C. sinensis $\mathrm{x}$ P. trifoliata), limoeiro 'Cravo' (Citrus limonia Osbeck) e laranja 'Caipira' [C. sinensis (L.) Osbeck]. As plântulas foram inoculadas pelo método da agulha infestada com o micélio do patógeno, retirado de colônias de $P$. parasitica com sete dias de idade em meio cenoura-agar.

As sementes dos genótipos foram lavadas em água corrente e desinfestadas superficialmente em álcool $70 \%$ e depois em solução a $25 \%$ de hipoclorito de sódio. Após secagem, foram colocadas assepticamente em meio de cultura específico para geminação e crescimento em meio de cultura. As plântulas foram cultivadas em tubos de vidro com capacidade de 20,0 ml contendo 3,0 $\mathrm{ml}$ de meio de cultura MT (Murashigue \& Tucker, 1969), suplementado com 0,1 $\mathrm{mg} / \mathrm{l}$ de Benzilamilopurina (BAP) e $1 \mathrm{mg} / \mathrm{l}$ de ácido indol butírico para induzir o enraizamento. As plântulas foram mantidas dez dias na ausência de luz, para estimular o estiolamento e, $\log$ a após foram submetidas a fotoperíodo de $18 \mathrm{~h}$ e à temperatura de $27^{\circ} \mathrm{C}$, por 30 dias.

Foram realizados pequenos ferimentos na região do colo das plântulas permitindo-se o contato planta-patógeno. A avaliação do experimento foi realizada aos dez dias após a inoculação do patógeno. Os dados da incidência da doença (\% de plantas doentes) foram transformados em $\sqrt{\mathrm{x}+0,5}$ para efeito de análise estatística e os tratamentos foram comparados pelo teste de Tukey ao nível $\mathrm{p}=0,05$ de probabilidade. Os dados da severidade da doença (comprimento da lesão em $\mathrm{mm}$ ) foram comparados pelo teste de Tukey ao nível $\mathrm{p}=0,05$ de probabilidade (Figura 1).

\section{Inoculação de $P$. parasitica usando casca destacada em diferentes genótipos}

Para o teste de método de inoculação de $P$. parasitica em porta-enxertos de citros, usando-se a casca destacada, foi montado um segundo experimento, que foi repetido duas vezes, conduzido em delineamento inteiramente casualizado, com quatro tratamentos formados dos genótipos avaliados laranja 'Azeda' (Citrus aurantium L.), tangerina 'Sunki' ( $C$. sunki Hort. ex Tan.), P. trifoliata 'Rubidoux', laranja 'Caipira', limoeiro 'Cravo' e citrumelo 'Swingle' ( $P$. trifoliata vs. $C$. paradisi Macf.) com 12 repetições, constituídas de 12 seções de casca. Cada experimento (2) foi realizado separadamente em delineamento inteiramente casualizado. Os genótipos $P$. trifoliata 'Rubidoux' e laranja 'Caipira', não 


\section{A. Siviero et al.}

foram testados no primeiro e segundo experimento, respectivamente, devido à falta de material vegetal para inoculacão (Tabela 1).

A inoculação de $P$. parasitica foi realizada usando-se seções de casca destacada de plantas de citros com quatro anos de idade. A inoculação foi realizada usando a parte interna das seções de casca, medindo 9,0 x 3,0 cm, removidas de plantas no campo. As cascas foram primeiramente desinfestadas com álcool $70 \%$, flambadas e em seguida inoculadas com um disco de micélio medindo $3,0 \mathrm{~mm}$ de diâmetro, retirado de colônias do patógeno com idade de sete dias, cultivado em meio de cenoura-agar. A face do disco correspondente a colônia do patógeno foi colocada em contato com a parte central interna da casca, por $4 \mathrm{~h}$, e em seguida retirado com pinça asséptica.

Após a inoculação, as cascas foram acondicionadas em sacos plásticos contendo algodão úmido e mantidas em bandejas plásticas em estufas B.O.D., a $27^{\circ} \mathrm{C}$, sob luz fluorescente, por $24 \mathrm{~h}$. A avaliação dos experimentos foi realizada aos seis dias após a inoculação através da medida da área da lesão provocada pelo patógeno, em $\mathrm{cm}^{2}$, feita com auxílio da mesa digitalizadora com uso de programa específico.

\section{Inoculação de $P$. parasitica pelos métodos do disco, da inserção sob casca e do contato planta sem ferimento- patógeno}

As plantas foram cultivadas em casa de vegetação, acondicionadas em sacos de polietileno contendo substrato comercial utilizado para formação de mudas cítricas ('Rendimax' + adubo peletizado de liberação lenta 'Osmocote', na formulação 18-05-09) e recebendo irrigações diárias e adubação foliar de reposição com fosfato monoamônico (MAP) e nitrocálcio na dosagem de 500 e 300 g para cada 20 1 de água, respectivamente. A inoculação foi realizada em hastes de plantas que apresentavam dois anos de idade e 5,0 a 7,0 $\mathrm{mm}$ de diâmetro e altura média de $0,50 \mathrm{~m}$. As hastes das plantas antes da inoculação foram superficialmente desinfestadas com algodão umedecido em álcool $70 \%$.

$\mathrm{O}$ terceiro experimento visou comparar três métodos de inoculação de $P$. parasítica em plantas jovens de citros. Os métodos testados foram da inserção sob casca, disco de meio de cultura infestado com o patógeno e contato - disco aderido na parte externa da casca da planta. Os genótipos (tratamentos): tangerinas 'Sunki' e 'Cleópatra' (Citrus reshni Hort. ex Tan), limoeiro 'Cravo', P. trifoliata 'Davis A' e 'Flying Dragon', citrumelos 'Sacaton' e 'Swingle' e citranges 'Carrizo' e 'Troyer' foram os mesmos para os três experimentos. Foram utilizadas 12 plantas (repetições) de cada genótipo em cada experimento, separadamente. Cada experimento foi montado em delineamento experimental inteiramente casualizado. Cada planta foi inoculada e avaliada uma única vez, para apenas um dos métodos em estudo, ou seja, uma mesma planta nunca foi usada para se testar mais de um método. As plantas foram inoculadas e avaliadas no mesmo local e data.

O método do disco consistiu na deposição do disco (micélio + patógeno) em hastes de plantas numa área da casca anteriormente demarcada com auxílio de um furador de rolhas. Primeiramente, removeu-se o disco de casca da planta e depositando-se em seguida o disco de meio de cultura infestado com $P$. parasitica sobre o cambio exposto. Posteriormente, recolocou-se o disco de casca destacada pressionando-se o inóculo contra o lenho, protegendo-se em seguida o ponto de inoculação, com esparadrapo.

O método de inserção de inóculo sob casca descrito por Grimm \& Hutchison (1973) e usada com sucesso em Israel, por Afek \& Sztejnberg (1990), consiste em introduzir um disco de micélio infestado com o patógeno foi inserido sob a casca da planta, semelhante ao processo de borbulhia de gemas. Cortes em T invertido foram realizados com bisturi estéril e após a inserção do disco contendo meio de cultura + micélio, a casca foi pressionada sobre o inóculo e a região protegida com esparadrapo e envolta com fita adesiva.

A metodologia definida como contato planta sem ferimentos-patógeno consistiu em depositar discos contendo meio + inóculo em contato externo com as plantas sem qualquer ferimento. $\mathrm{O}$ disco de meio de cultura contendo o patógeno foi pressionado junto à planta e levemente esmagado na região de inoculação, com auxílio de esparadrapo, promovendo o contato planta-patógeno. A área de inoculação foi então protegida com gaze e algodão umedecido recobrindose com fita adesiva.

Nos três experimentos avaliados utilizou-se disco de meio de cultura infestado com micélio de $P$. parasitica medindo 3,0 mm de diâmetro. Os discos foram retirados de colônias com sete dias e cultivado em meio de cenoura-agar mantidas em estufa B.O.D. a $25{ }^{\circ} \mathrm{C}$ e $24 \mathrm{~h}$ de luz. Todas as plantas após inoculadas foram mantidas em temperatura de $22 \pm 2{ }^{\circ} \mathrm{C}$ e umidade relativa do ar em torno de $80 \pm 10 \%$. A avaliação foi realizada aos 14 dias após a inoculação através da medida do comprimento das lesões (mm).

\section{Inoculação de $P$. parasitica usando palito-de-dente e agulha infestados}

O quarto experimento, que visou avaliar dois métodos de inoculação de $P$. parasitica em citros, específicos para avaliação da doença na fase de plântulas, consistiu da inoculação de palitos-de-dente e agulhas infestados com o patógeno. Foram avaliados 29 genótipos de citros e gêneros correlatos (tratamentos) (Tabela 2) para cada método testado (palito e agulha) e dez plantas avaliadas de cada genótipo (repetições). Cada planta, constituída de uma parcela experimental, foi inoculada e avaliada apenas uma única vez, para cada método em estudo. Os experimentos foram conduzidos no mesmo local, mas montados separadamente, seguindo o esquema de delineamento inteiramente casualizado para ambos. As inoculações e avaliações foram realizadas na mesma data. Os genótipos P. trifoliata 'Rubidoux' e 'Davis A'; limoeiro 'Cravo'; limão 'Siciliano' e a tangerina 'Sunki' atuaram respectivamente, como padrões de resistência, moderada resistência e suscetibilidade a $P$. parasitica (Feichtenberger, 2001). 
Avaliação de métodos de inoculação de Phytophthora parasitica em plântulas...

As plantas foram obtidas através de sementes extraídas de frutos da safra 1998/99. As sementes, após extração e beneficiamento, foram tratadas com o fungicida QuintozenePentacloronitrobenzeno (PCNB), em pó molhável, na dose de $400 \mathrm{~g} / 100 \mathrm{~kg}$ semente. Uma parte das sementes foi plantada e outra armazenada em câmara fria a $5^{\circ} \mathrm{C}$. A semeadura foi realizada em tubetes contendo substrato comercial 'Plantimax', usado na formação de porta-enxerto de citros, com adição de adubo peletizado na formulação 18-05-09 e na dose de $40 \mathrm{~g}$ de adubo para cada 101 de substrato. As bandejas contendo tubetes foram mantidas em casa de vegetação, recebendo irrigação diária com água isenta de inóculo do patógeno.

Os palitos-de-dente foram cortados a $1 / 4$ do seu tamanho normal, afilados em uma das pontas, esterilizados com álcool $70 \%$, fervidos em água por três vezes, com sucessivas trocas de água, visando extrair possíveis substâncias tóxicas e, finalmente, autoclavados. A seguir, os palitos foram mantidos por sete dias em placas de Petri contendo meio de cultura (CA) inoculado com discos de micélio de $P$. parasitica. No momento em que o micélio de $P$. parasitica recobriu todos os palitos considerou-se que estavam prontos para a inoculação. A inoculação consistiu na inserção do palito infestado pelo patógeno nas hastes de plantas a uma altura de 2,0 a 3,0 cm do colo. No ponto de inoculação, os tecidos foram previamente perfurados com agulha estéril para facilitar a entrada do palito infestado, que permaneceu na planta até a avaliação final.

Para o outro método utilizou-se uma agulha de metal desinfestada com álcool 70\%. A agulha foi infestada com $P$. parasitica cultivado em meio CA, com idade de sete dias. A haste da planta foi perfurada com a agulha até a extremidade oposta, em seguida, a agulha infestada foi novamente introduzida no ponto de inoculação e retirada, posteriormente. O ponto de inoculação foi protegido com algodão umedecido e vedado com auxílio de fita adesiva.

Após a inoculação as plantas foram mantidas em câmara úmida com $90 \pm 5 \%$ de umidade relativa do ar e temperatura de $24 \pm 2{ }^{\circ} \mathrm{C}$. A avaliação foi realizada 32 dias após a inoculação medindo-se o comprimento das lesões em $\mathrm{cm}$. Os dados brutos, obtidos do experimento que testou o método de inoculação usando a agulha infestada, foram transformados em $\sqrt{\mathrm{x}+0,5}$ para efeito de análise estatística, devido ao grande número de medidas obtidas das inoculações em plantas resistentes ser zero comparando-se os tratamentos pelo teste de Tukey ao nível $\mathrm{p}=0,05$ de probabilidade.

\section{RESULTADOS E DISCUSSÃO}

\section{Avaliação in vitro de porta-enxertos à gomose}

As médias da porcentagem de plantas doentes para os genótipos $P$. trifoliata 'Davis A', citrange 'Carrizo', limoeiro 'Cravo' e laranja 'Caipira' foram: 6,0; 7,0; 38,0 e 73,0\%, respectivamente. $\mathrm{O}$ comprimento médio das lesões das plantas doentes para os genótipos testados foi de 2,00; 3,00; 31,15 e $46,83 \mathrm{~mm}$ para os genótipos $P$. trifoliata 'Davis A', citrange 'Carrizo', limoeiro 'Cravo' e laranja 'Caipira', respectivamente (Figura 1).

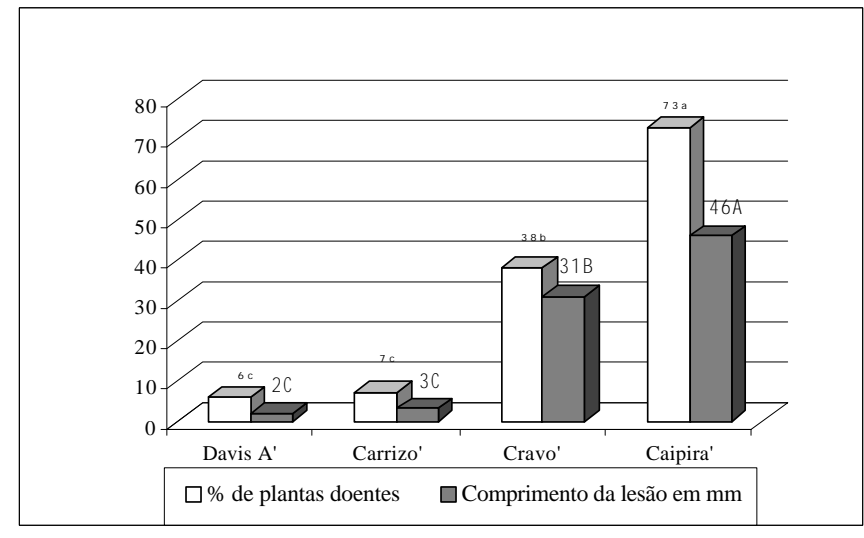

FIG. 1 - Porcentagem de plantas doentes e comprimento médio (mm) de lesões causadas Phytophthora parasitica em quatro genótipos de citros (Citrus spp.) dez dias após inoculação. Médias seguidas pela mesma letra para a porcentagem de plantas doentes (incidência) e o comprimento de lesão (severidade) não diferem entre si pelo teste de Tukey, ao nível de $5 \%$ de probabilidade. [CV (\%): Incidência $=22,87$ e Severidade $=8,98]$.

O método de inoculação in vitro distinguiu genótipos de porta-enxerto para citros quanto à resistência a $P$. parasitica e pode ser utilizado na seleção precoce na fase de plântulas. Os resultados da reação de resistência dos genótipos em campo, citados na literatura (Feichtenberger, 2001), estão em concordância com as reações encontradas in vitro. $\mathrm{O}$ método permite avaliar um grande número de genótipos em pequeno espaço físico e de tempo. Entre as desvantagens do seu uso estão a exigência de laboratório de cultivo in vitro e mão-deobra especializados podendo apenas ser útil para avaliar genótipo em produção, o que leva à seleção tardia de material, nem sempre desejável em programas de melhoramento de citros.

Utilizando-se o método de inoculação em condições

TABELA 1 - Áreas médias de lesões, em $\mathrm{cm}^{2}$, provocadas pela inoculação de Phytophthora parasitica inoculado em casca de destacada em portaenxertos de citros (Citrus spp.)

\begin{tabular}{lcc}
\hline \hline Genótipo & Experimento 1 & Experimento 2 \\
\hline Tangerina 'Sunki' (S) & $9,662 \mathrm{a}$ & $8,554 \mathrm{a}$ \\
Laranja ‘Azeda' (R) & $9,506 \mathrm{a}$ & $9,817 \mathrm{a}$ \\
Laranja 'Caipira'(S) & $7,991 \mathrm{ab}$ & - \\
Citrumelo 'Swingle' (R) & $5,773 \mathrm{bc}$ & $8,016 \mathrm{a}$ \\
Lim๕iro 'Cravo' (MS) & $5,148 \mathrm{c}$ & $8,733 \mathrm{a}$ \\
P. trifoliata 'Rubidoux' (R) & - & $8,176 \mathrm{a}$ \\
\hline D. M. S. & 2,284 & 1,952 \\
Coeficiente de variação (\%) & 23,61 & 19,58 \\
\hline
\end{tabular}

Médias seguidas pela mesma letra na mesma coluna não diferem entre si pelo teste de Tukey, ao nível de $5 \%$ de probabilidade. $(\mathrm{S}=$ suscetível, $\mathrm{MS}=$ moderadamente suscetível e R = resistente, segundo Pompeu Junior, 1991). 
A. Siviero et al.

TABELA 2 - Tamanho médio de lesões em cm, provocadas por Phytophthora parasitica em plântulas em genótipos de citros (Citrus spp.) inoculados pelo método da agulha infestada

\begin{tabular}{|c|c|}
\hline Genótipo & Tamanho da lesão em cm \\
\hline Citrange 'Troyer' (Citrus sinensis x Poncinus trifoliata) & $0,858 \mathrm{e}$ \\
\hline Citrange 'Carrizo'(C. sinensis x $P$. trifoliata $)$ & 1,015 dce \\
\hline Citrange 'Morton' $(C$. sinensis x $P$. trifoliata $)$ & 0,984 dce \\
\hline Citrange 'Troyer tetraploide' & 1,141 dce \\
\hline Citrange 'Carrizo tetraploide' & 1,018 dce \\
\hline Tangerina ‘Sunki’ vs.P. trifoliata 'English’ & 0,982 dce \\
\hline Tangerina 'Cleópatra' vs.P. trifoliata 'Swingle' & 0,959 dce \\
\hline Limão 'Cravo' vs. citrange 'Carrizo' & $0,875 \mathrm{e}$ \\
\hline Tangerina 'Cleópatra' vs.P. trifoliata & 1,112 dce \\
\hline Tangerina 'Cleópatra' vs.P. trifoliata 'English' & 0,999 dce \\
\hline Tangerina 'Cleópatra' vs.P. trifoliata 'Swingle' & $0,957 \mathrm{e}$ \\
\hline Tangerina 'Cleópatra' vs.P. trifoliata 'Swingle' & $0,939 \mathrm{e}$ \\
\hline Tangerna 'Clementina' $(C$. reticulata) vs. $P$. trifoliata & 1,190 dce \\
\hline Tangerina 'Cleópatra vs. P. trifoliata 'Christhian' & $1,227 \mathrm{dc}$ \\
\hline Tangerina 'Cleópatra' vs.P. trifoliata 'Rubidoux' & 0,982 dce \\
\hline Tangerina 'Changsha' vs. P. trifoliata 'English large' & 1,154 dce \\
\hline Torange Sämese vs. P. trifoliata 'Gotha-road' & $1,282 \mathrm{c}$ \\
\hline Tangerina 'Changsha' vs.P. trifoliata 'English small' & 1,181 dce \\
\hline Limão 'Cravo' vs.P. trifoliata 'Swingle' & 1,198 dce \\
\hline Tangerina 'Sunki' vs.P. trifoliata 'Benecke' & 0,968 dce \\
\hline (Lar. 'Shamouti' vs. lar. 'Mediterranean') x P. trifoliata 'Christiansen' & 0,866 dce \\
\hline Tangerina 'Miaray'( $C$. reticulata) & 0,962 dce \\
\hline Limão 'Cravo' vs. $P$. trifoliata 'Swingle' & $1,595 \mathrm{~b}$ \\
\hline Limão 'Siciliano’- suscetível & $2,139 \mathrm{a}$ \\
\hline Tangerina 'Sunki’ - suscetível & $3,303 \mathrm{a}$ \\
\hline Limão 'Cravo’' média resistência & 1,187 dce \\
\hline P. trifoliata 'Rubidoux' - resistente & $0,861 \mathrm{e}$ \\
\hline P. trifoliata 'Davis A' - resistente & 0,996 dce \\
\hline
\end{tabular}

Médias seguidas pela mesma letra não diferem entre si pelo teste de Tukey, ao nível de 5\% de probabilidade.

axênicas, a partir das sementes das plantas, num prazo de 40 dias conseguiu-se obter resposta de reação dos genótipos ao patógeno. A técnica pode ser de grande utilidade em trabalhos envolvendo seleção de resistência varietal de plantas cítricas ao patógeno.

\section{Avaliação de gomose dos citros em inoculação de $P$. parasitica em casca destacada}

$\mathrm{Na}$ Tabela 1 são mostrados os dados do tamanho das lesões em $\mathrm{cm}^{2}$, provocadas pela inoculação de $P$. parasitica em secções de cascas de destacadas de diferentes genótipos usados como porta-enxerto para citros.

Analisando-se os dados do primeiro experimento observa-se que as menores áreas de lesão foram apresentadas pelo limoeiro 'Cravo' e citrumelo 'Swingle' que não coincidem com aquelas relatadas na literatura (Rossetti, 1947; Pompeu Junior, 1991; Feichtenberger, 2001). Os genótipos, laranja 'Azeda', citrumelo 'Swingle' e o limoeiro 'Cravo', respectivamente, resistentes e moderadamente resistentes ao patógeno, se comportaram como suscetíveis nos dois experimentos. No segundo experimento, todos os genótipos se comportaram igualmente às inoculações com a relação à reação ao patógeno, não havendo diferenças significativas nas áreas de lesão apresentadas por eles. Os resultados destas inoculações mostram que esta metodologia não foi adequada para discriminar genótipos de citros quanto à doença.

Avaliação das inoculações de $P$. parasitica pelos métodos do disco, da inserção sob casca e do contato planta sem ferimento-patógeno

As plantas inoculadas pelo método de contato entre plantas sem ferimento e patógeno não apresentaram lesões de $P$. parasitica. Através das médias do comprimento das lesões em mm, considerando os dois métodos (disco e inserção), que foram comparadas com as médias das plantas avaliadas dos nove genótipos de citros testados, para cada um dos dois métodos de inoculação de $P$. parasitica (Tabela 3) pode-se verificar que o patógeno necessita de ferimento para penetrar na planta e causar doença. O método da inserção sob casca foi o que proporcionou lesões maiores em comprimento quando comparado com o método do disco, no entanto, os dois métodos conseguiram discriminar portaenxertos de citros quanto à resistência a gomose (Tabela 3).

O método do disco usado desde o início do século passado em inoculações de Phytophthora spp. por Klotz \& Fawcett, (1930) e Rossetti (1947), em plantas adultas no 
Avaliação de métodos de inoculação de Phytophthora parasitica em plântulas...

TABELA 3 - Comprimento médio de lesões $(\mathrm{mm})$, provocadas por Phytophtora parasitica em portaenxertos de citros (Citrus spp.) usando os métodos do disco e de inserção sob casca

\begin{tabular}{lcc}
\hline \hline Genótipo & Disco & Inserção sob casca \\
\hline Tangerina 'Sunki' (S) & 14,75 & 15,88 \\
Limoeiro 'Cravo' (MS) & 9,91 & 12,58 \\
P. trifoliata 'Davis A' (R) & 8,33 & 12,50 \\
Citrange 'Troyer' (R) & 6,75 & 12,06 \\
Tangerina 'Cleópatra' (MS) & 6,25 & 11,50 \\
Citrumelo 'Sacaton'(R) & 7,25 & 9,91 \\
Citrumelo ‘Swingle'(R) & 6,33 & 10,17 \\
Citrange 'Carrizo' (R) & 5,16 & 8,25 \\
P. trifoliata 'F. Dragon' (R) & 5,91 & 7,41 \\
\hline Média para método & $7,06 \mathrm{a}$ & $10,02 \mathrm{~b}$ \\
Método x genótipo & & $1.277^{\text {n.s. }}$ \\
\hline
\end{tabular}

Médias seguidas das mesmas letras não diferem entre si pelo teste Tukey, ao nível de 5\% de probabilidade. ( $\mathrm{S}=$ suscetível, $\mathrm{MS}=$ moderadamente suscetível; $\mathrm{R}=$ resistente, segundo Fawcett, 1936). [CV $(\%)=36,31]$.

campo, se mostrou eficiente para avaliar a resistência ao patógeno em plantas jovens em casa de vegetação.

O método da inserção sob casca, descrito por Grimm \& Hutchison (1973) e usado em Israel por Afek \& Stezjnberg (1990), gerou lesões de comprimento significativamente maiores em comprimento em comparação com o método do disco (Tabela 3). O maior comprimento das lesões observado pelo método da inserção sob casca pode ser atribuído ao fato de que no momento da incisão e abertura da casca para inserção do disco de micélio a área do descolamento da casca para exposição do lenho é maior de que aquela provocada pelo disco $\left(\cong 7,05 \mathrm{~mm}^{2}\right)$. O controle da homogeneidade da área da casca da planta exposta/descolada para inoculação, via inserção sob casca, depende de fatores como genótipo e, estado fisiológico da planta. Algumas plantas, mesmo sendo submetidas aos mesmos tratos culturais, são mais sensíveis ao descolamento da casca do lenho do que outras. Considerando estes fatos recomenda-se a adoção do método do disco nas inoculações de plantas em casa de vegetação e campo para avaliação da resistência à gomose.

\section{Inoculação de $P$. parasitica em plantas jovens usando palito- de-dente e agulha infestados}

Os dados das inoculações com o palito-de-dente infestado com P. parasitica não foram analisados devido ao número excessivo de plântulas que não apresentaram lesões. Observou-se que em parte das plantas, no momento da inserção do palito, ocorreu um fendilhamento da haste da plântula, contribuindo para não ocorrência das lesões. Analisando-se os dados (Tabela 3), observa-se que os cinco genótipos usados como padrões: $P$. trifoliata 'Rubidoux' e 'Davis A' (altamente resistentes); limoeiro 'Cravo' (moderadamente resistente) e o limoeiro 'Siciliano' e tangerina 'Sunki' (altamente suscetíveis a $P$. parasitica), apresentaram médias de 0,$86 ; 0,99 ; 1,19 ; 1,59$ e 3,30 cm de comprimento, respectivamente. O método se mostrou seguro e eficiente na discriminação da resistência de genótipos patógeno com resultados concordantes com as reações de campo (Fawcett, 1923; Rossetti, 1947). Os demais genótipos testados (citrandarins) apresentaram reações intermediárias de resistência a $P$. parasitica. O método da agulha mostrou-se, prático, rápido e eficiente na discriminação de plantas jovens para resistência ao patógeno.

Entre os métodos de avaliação testados na fase de plântulas e in vitro conclui-se que o método da agulha é o mais indicado. Em plantas jovens, o método do disco e o da inserção sob casca foram os melhores. Para a metodologia de avaliação da lesão, no caso de plântulas, a quantificação da doença pode ser feita pela percentagem de plantas doentes e/ ou pela medida do comprimento da lesão. No caso das plantas jovens a avaliação da doença, se possível, deve ser feita medindo-se a área total da lesão ou ainda utilizando-se o comprimento da lesão.

\section{REFERÊNCIAS BIBLIOGRÁFICAS}

AFEK, U. \& SZTEJNBERG, A. A rapid method for evaluating citrus seedlings for resistance to foot rot caused by Phytophthora citrophthora. Plant Disease 74:66-68. 1990.

AGUILAR-VILDOSO, C.I. \& POMPEU JUNIOR, J. Inoculação de Phytophthora parasitica em caules de variedades cítricas pelo método do palito. Fitopatologia Brasileira 22:240. 1997. (Resumo).

FAWCETT, H.S. Gummosis on citrus. Journal of Agricultural Research 24:235-255. 1923.

FAWCETT, H.S. \& BITANCOURT, A.A. Occurrence, pathogenicity and temperature relations of Phytophthora species on citrus in Brazil and other South American countries. Arquivos do Instituto Biológico 11:107-119. 1940.

FEICHTENBERGER, E. Doenças incitadas por Phytophthora em citros. In: Luz, E.D.M.N., Matsuoka, K., Santos, A.F. \& Bezerra, J.L. (Eds.). Doenças causadas por Phytophthora no Brasil. Campinas. Livraria Rural. 2001. pp.283-342.

GRAHAM, J.H. \& TIMMER, L.W. Phytophthora disease of citrus. In: Plant Diseases of International Importance. Kummer, J. (Ed.). N. Jersey. Prentice-Hall. 1992. pp.250-269.

GRIMM, G.R. \& HUTCHISON, D.J. A procedure for evaluating resistance of citrus seedlings to Phytophthora parasitica. Plant Disease Reporter 57:669-672.1973.

KLOTZ L.J. \& FAWCETT, H.S. The relative resistance of varieties and species of citrus to Pythiacystis gummosis and other bark diseases. Journal of Agricultural Research 2:415-425. 1930.

MURASHIGUE, T. \& TUCKER, W. F. Growth factor requirements of citrus tissue culture. In: International Citrus Symposium, 1, Riverside. 1969. pp.1155-1166.

POMPEU JUNIOR, J. Porta-enxerto. In: Rodriguez, O., Viegas, F., Pompeu Junior, J. \& Amaro, A.A. (Eds.) Citricultura Brasileira. Campinas. Fundação Cargill. 1991. pp.116-152.

ROSSETTI, V. Estudos sobre a gomose de Phytophthora dos citros I - Suscetibilidade de diversas espécies cítricas a algumas espécies de Phytophthora. Arquivos do Instituto Biológico 18:97-124. 1947.

SIVIERO, A. Métodos de inoculação da Phytophthora parasitica e 


\section{A. Siviero et al.}

mapeamento de QTLs de resistência em híbridos de Citrus sunki vs. Poncirus trifoliata a gomose. (Tese de Doutorado) Botucatu. Faculdade de Ciências Agronômicas. 2001.

SMITH, G.S., HUTCHISON, D.J. \& HENDERSON, T. Screening sweet orange citrus cultivars for relative susceptibility to Phytophthora foot rot. Proceedings Florida State Horticultural Science 110:64-66. 1987.
SMITH, G.S., HUTCHISON, D.J. \& HENDERSON, T. Comparative use of soil infested with chlamydospores to screen for relative susceptibility to Phytophthora foot rot in citrus cultivars. Plant disease 75:402-405. 1991.

WHITESIDE, J.O. Zoospore-inoculation techniques for determining the relative susceptibility of citrus rootstocks to foot rot. Plant Disease Reporter 58:713-717. 1974. 